\title{
Synthesis of Q-particulate CdS Thin Films by Using Surface Adsorbent in Electrochemically Induced Chemical Deposition (EICD) Technique
}

\author{
Koichi YAMAgUCHI, Tsukasa YoShIDA, Noboru YASUFUKU, Takashi SUGIURA, \\ and Hideki MINOURA*
}

Department of Chemistry, Faculty of Engineering, Gifu University (Yanagido 1-1, Gifu 501-1193, Japan)

Received June 15, 1999 ; Accepted August 4, 1999

\begin{abstract}
Electrochemically induced chemical deposition (EICD) of nanocrystalline CdS thin films has been realized in an aqueous mixture of $\mathrm{CdSO}_{4}$, thioacetamide (TAA) and 2-mercaptoethanol (ME). Increasing the $\mathrm{ME}$ concentration as $0,2,4$ and $6 \mathrm{mM}\left(\mathrm{M}=\mathrm{mol} \mathrm{dm}^{-3}\right)$ in the reaction bath containing $0.05 \mathrm{M} \mathrm{CdSO}_{4}$ and $0.1 \mathrm{M} \mathrm{TAA}$ resulted in a decrease of the crystal size as $23,6.4,4.8$ and $4.1 \mathrm{~nm}$, respectively. The bandgap energies of direct transition, estimated from the photocurrent action spectra of the deposited thin-film electrodes, increased as $2.43,2.57,2.65$ and $2.69 \mathrm{eV}$ in the same order, clearly exhibiting the size quantization effects expected for such nano-particulate CdS thin films.
\end{abstract}

Key Words : Q-CdS, Thin Film, Electrodeposition, Size Quantization Effect

\section{Introduction}

Cadmium sulfide (CdS) is an important semiconductor finding applications in various opto-electronic devices. Although there are many reports on chemi$\mathrm{cal}^{1)}$ and electrochemical ${ }^{21}$ deposition of CdS films in aqueous solutions, the film growth has often suffered from incorporation of solid particles formed in solutions. We have recently shown that local $\mathrm{pH}$ increase by electroreduction of proton at the substrate can promote the atom-by-atom crystal growth of $\mathrm{CdS}$ in acidic chemical bath. ${ }^{3}$ Detailed analysis of the growth process revealed that the process should be regarded as an electrochemically induced chemical deposition (EICD). ${ }^{3)}$ The CdS thin films deposited by EICD retained an ordered structure consisting with highly crystallized CdS particles, since the film growth was not disturbed by solution phase reaction but was achieved by the growth of CdS crystallites.

Meanwhile, nano-scale crystals are of academic interests in their different properties from bulk materials due to the size quantization effect ${ }^{4,5)}$ and have been studied also for their potential application as photocatalysts. ${ }^{6,7)}$ Such nanoparticles are often referred as Q-particles. ${ }^{6}{ }^{6}$ It is therefore interesting to develop a method to obtain Q-particulate CdS thin films. ${ }^{8,9)}$ However, it is usually difficult to obtain a "thick" Q-CdS film, because the crystal growth during the film growth has to be avoided.

Since surface chemical reactions play a major role in the film growth by the EICD method, capping the reaction sites by surface adsorbents is expected to hinder the crystal growth and promote formation of nuclei, thus altering the film growth from that achieved by crystal growth to that by continuous formation of CdS Q-particles. Thiols are known to act as strong adsorbents to CdS surface. ${ }^{10)}$ In this study, we have attempted to control the crystal growth in the EICD process by adding 2-mercaptoethanol (ME) to the reaction bath.

\section{Experimental}

Commercially available purest chemicals were used as received, except thioacetamide (TAA) which was recrystallized in benzene. An indium-tin oxide (ITO) or an $\mathrm{SnO}_{2}$-coated glass was used as a conducting substrate.

The conditions for the film deposition were similar to those previously reported. ${ }^{3)}$ An aqueous solution containing $0.05 \mathrm{M} \mathrm{CdSO}_{4}\left(\mathrm{M}=\mathrm{mol} \mathrm{dm}{ }^{-3}\right), 0.1 \mathrm{M} \mathrm{TAA}$ and 2-mercaptoethanol (ME) whose concentration varying between 0 and $6 \mathrm{mM}$ served as a reaction bath. The $\mathrm{pH}$ of the reaction bath was adjusted to 2.4 by adding $\mathrm{H}_{2} \mathrm{SO}_{4}$. The deposition of film was carried out at $-0.61 \mathrm{~V}$ vs. $\mathrm{Ag} / \mathrm{AgCl}$ and at $70{ }^{\circ} \mathrm{C}$ for $3 \mathrm{~h}$.

Film thickness was measured by a Kosaka Lab. SE-2300 surface profilometer. X-ray diffraction (XRD) spectra were obtained by a Rigaku RAD-2R using $\mathrm{CuK} \alpha$ radiation. Surface morphology of the deposited films was observed by a Topcon ABT-150FS scanning electron microscope (SEM). UV-VIS absorption spectra were measured by a Hitachi U-3500 spectrophotometer.

The current-potential curves, both in the dark and under illumination by a $500 \mathrm{~W}$ xenon lamp (intensity $=10 \mathrm{~mW} / \mathrm{cm}^{2}$ ) were measured at the deposited CdS thin films in an aqueous solution of $1 \mathrm{M} \mathrm{Na}_{2} \mathrm{~S}$. Monochromatic light generated by a Nikon G-250 monochrometer was used for measuring photocurrent action spectra.

\section{Results and Discussion}

When the mixed solution was heated, it gradually 
became turbid due to the precipitation of CdS. While the color of precipitates was orange when $\mathrm{ME}$ was absent, it became yellow to pale yellow upon increasing the concentration of ME. Cathodic electrolysis at the substrate in this reaction bath resulted in a deposition of a transparent thin film. The deposited films showed a similar color change to that of the precipitates by adding ME. The film thickness only slightly decreased as 110, 105, 101 and $96 \mathrm{~nm}$, upon increasing the $\mathrm{ME}$ concentrations as $0,2,4$ and $6 \mathrm{mM}$. Addition of $\mathrm{ME}$ at higher concentrations than $10 \mathrm{mM}$ completely hindered the film growth, although formation of CdS precipitates in solution did occur. It should also be noted that no film growth was observed when the substrates were simply immersed in the deposition bath, indicating that accumulation of CdS particles formed in the bath onto the substrate does not contribute to the film growth, as typically expected for the EICD process. ${ }^{3)}$

$\mathrm{X}$-ray diffractograms of the deposited CdS thin films are shown in Fig. 1. While the characteristic peak from the (200) planes of the cubic structure, ${ }^{11}$ i.e. $2 \theta=30.8^{\circ}$, was clearly seen, the diffraction peaks characteristic of the hexagonal structure ${ }^{12)}$ were absent, clearly indicating cubic structure of the deposited film. The precipitates formed in the bath have also been identified as cubic CdS in a separate experiment. This is a remarkable difference from the previous report where only hexagonal CdS was produced by using $\mathrm{CdCl}_{2}$ as a $\mathrm{Cd}^{2+}$ source. ${ }^{3)}$ It is evident that counter anion of the $\mathrm{Cd}$ salt plays an important role in the crystal growth.

With increasing the concentration of ME, the diffraction peaks became broader as shown for the (111)

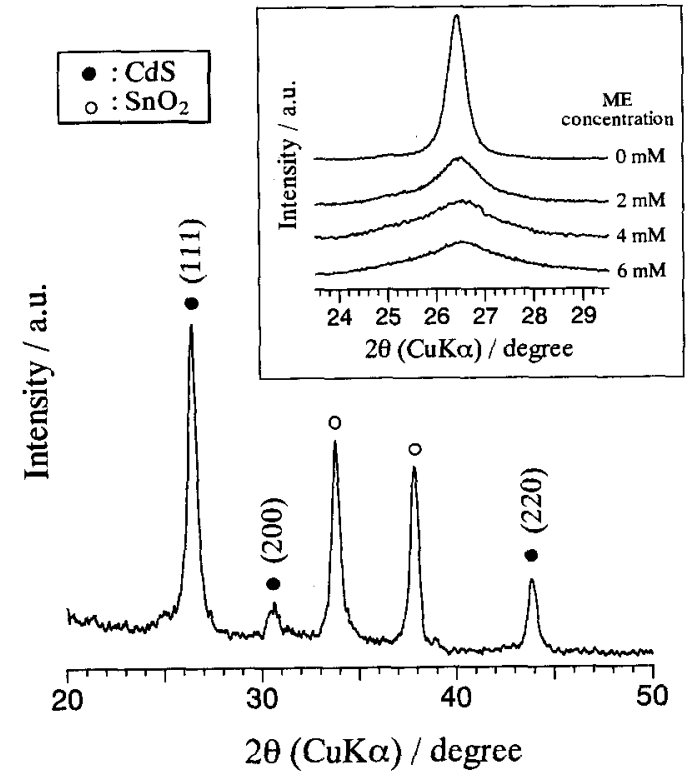

Fig. 1 X-ray diffractograms of $\mathrm{CdS}$ thin films deposited on $\mathrm{SnO}_{2}$-coated glass substrates in $0.05 \mathrm{M} \mathrm{CdSO}_{4}+0.10 \mathrm{M}$ TAA + ME mixed aqueous solutions. The full spectrum is that of the film deposited without ME for which Miller indices of cubic CdS are indicated. The inset shows the broadening of the (111) diffraction peaks by the addition of $\mathrm{ME}$ at $0,2,4$, and $6 \mathrm{mM}$. diffraction peak in the inset of Fig. 1. The size of CdS crystallite has been estimated from the full-width at half-maximum of the (111) diffraction peak by using Scherrer's equation. Increasing the ME concentration as $0,2,4$ and $6 \mathrm{mM}$ was found to decrease the crystal size as $23,6.4,4.8$ and $4.1 \mathrm{~nm}$, respectively. ME is known to be strongly adsorbed on the surface of CdS owing to the high stability of the $\mathrm{Cd}^{2+}-\mathrm{SCH}_{2} \mathrm{CH}_{3}$ bond as recognized from the large formation constant of $\mathrm{Cd}(\mathrm{ME})_{2}\left(\log \beta_{2}=28.8\right){ }^{13)}$ It is supposed that the adsorption of ME onto the reaction sites at the CdS surface hinders the atom-by-atom crystal growth. However, continuous electroreduction of proton promotes further formation of CdS at the vicinity of the substrate in the EICD process. ${ }^{3}$ Consequently, the addition of $\mathrm{ME}$ to the reaction bath is expected to favor the formation of nuclei, thus yielding nanocrystalline CdS films.

The surface morphologies of the deposited CdS films are shown in Fig. 2. When ME was absent (Fig. 2a), bulky particles of $200-400 \mathrm{~nm}$ in diameter are seen. Each particle is composed of triangular shaped crystallites of a few tens of nanometer. This surface morphology is totally different from the one deposited in the $\mathrm{CdCl}_{2}$-TAA system, where highly crystallized hexagonal CdS particles were clearly seen. ${ }^{3)}$ When $\mathrm{ME}$ is added (Fig. 2b), the size of the deposited particles becomes much smaller (ca. $100 \mathrm{~nm}$ in diameter) and they seem to consist with very fine crystals of CdS.

In Fig. 3, the current-potential characteristics of a nanocrystalline CdS thin-film electrode prepared with $2 \mathrm{mM} \mathrm{ME}$ and a well-grown polycrystalline CdS thinfilm electrode prepared without ME are compared. The photoelectrochemical activity of the polycrystalline electrode is rather poor, showing a gradual increase of photocurrent with increasing the applied bias and no saturation of photocurrent. Such a behavior is typically expected for a polycrystalline thin-film electrode, since photogenerated charge carriers have to move across a number of grain boundaries which can act as charge recombination centers. ${ }^{14)}$ On the other hand, I-V characteristics of the nanocrystalline electrode are greatly improved so that only a small bias against the photocurrent onset potential leads to a saturation of photocurrent. This superior I- $\mathrm{V}$ behavior of the nano-particulate CdS electrode can be reasonably understood by a model proposed by Hodes $e t$

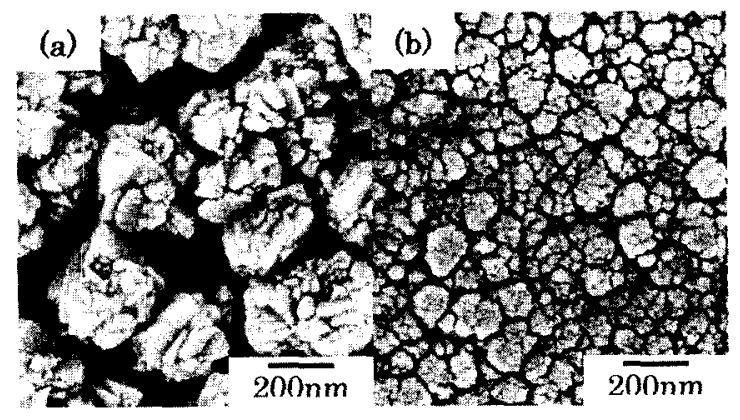

Fig. 2 SEM photographs of the CdS thin films deposited without ME (a) and in the presence of $4 \mathrm{mM} \mathrm{ME} \mathrm{(b).}$ 


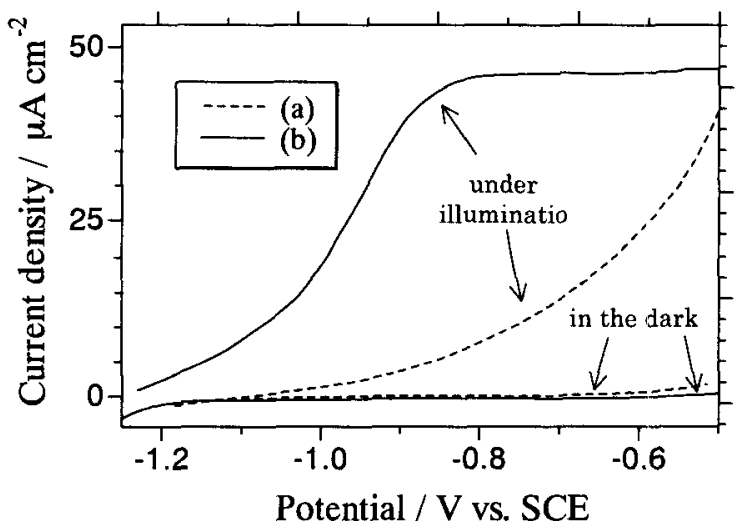

Fig. 3 Current-potential curves at the nano-particulate CdS thin-film electrode deposited from a bath containing 2 $\mathrm{mM} \mathrm{ME}$ (solid line) and polycrystalline CdS thin-film electrode deposited without ME (dotted line), both in the dark and under white light illumination by a Xe lamp at the intensity of $10 \mathrm{~mW} / \mathrm{cm}^{2}$.

al. ${ }^{14)}$ In their model, when each nano-particulate semiconductor is in contact with the electrolyte containing reductants, photogenerated holes can be readily removed by the reductants, whereas remaining electrons flows to the conducting substrate, thus rectifying the flow of holes and electrons.

The photoelectrochemical properties of the nanoparticulate thin films have been investigated by means of action spectra in more detail (Fig. 4). The photocurrent onset moves towards shorter wavelength with increasing the concentration of ME. This blue shift has also been observed in the UV.VIS absorption spectra of the films. The higher ME concentration was used, the higher incident photon-tocurrent conversion efficiency (IPCE) was reached. Due to the light scattering and interference caused by the deposited films, it was difficult to determine the bandgap energies $\left(E_{g}\right)$ from the absorption onset in the UV-VIS spectra. Since the IPCE is expected to be proportional to the absorption coefficient $(\alpha)$ near the absorption onset, ${ }^{15)}(\mathrm{IPCE} \times h \nu)^{2}$ was plotted instead of $(\alpha h \nu)^{2}$ versus $h \nu$ to determine the band gap energies of direct transition (Fig. 4, inset). In Table 1 are summarized the change of the crystal size and $E_{\mathrm{g}}$ determined from the abscissa of the linear fitting to the (IPCE $\times h \nu)^{2}$ vs. $h \nu$ plot with respect to the added ME concentrations, Theoretical $E_{\mathrm{g}}$ values predicted from the crystal size are compared, as calculated by using a finite depth well model proposed by Nosaka $e t$ $a l .{ }^{5)}$ The $E_{\mathrm{g}}$ of bulk CdS has been assumed as equal to that of the film deposited without ME $(2.43 \mathrm{eV})$ for the calculation, since the energy shift becomes negligibly small when the crystal size exceeds $20 \mathrm{~nm}{ }^{5}$ ) The experimental and theoretical $E_{\mathrm{g}}$ values are in good agreement. The observed enlargement of $E_{\mathrm{g}}$ is therefore reasonably attributed to the size quantization effect for the individual crystallites that consist the film.

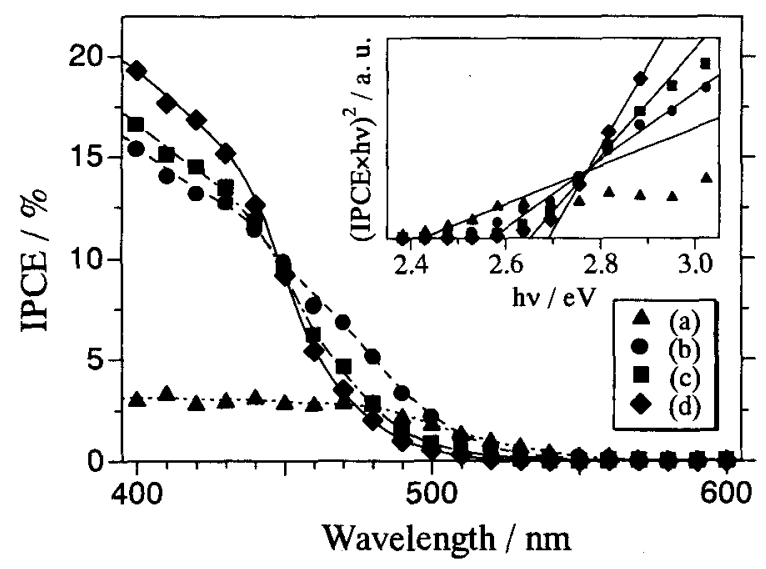

Fig. 4 Photocurrent action spectra measured under monochromatic light illumination and with fixed bias $(-0.7 \mathrm{~V}$ vs. SCE) for the CdS thin-film electrodes prepared from the baths containing (a) $0 \mathrm{mM}$, (b) $2 \mathrm{mM}$, (c) $4 \mathrm{mM}$, (d) $6 \mathrm{mM}$ of ME. The inset shows the $(\mathrm{IPCE} \times h \nu)^{2}$ vs. $h \nu$ plots for the bandgap determination.

Table 1 Change of crystal size and $E_{\mathrm{g}}$ dependent on the $\mathrm{ME}$ concentration in the deposition bath, compared to the theoretical $E_{\mathrm{g}}$ values predicted from the crystal size using a finite depth well model. ${ }^{5)}$

\begin{tabular}{cccc}
\hline $\begin{array}{c}{[\mathrm{ME}] /} \\
\mathrm{mM}\end{array}$ & $\begin{array}{c}\text { Size of } \\
\text { crystallite/nm }\end{array}$ & $\begin{array}{c}\mathrm{Eg} / \mathrm{eV} \\
\text { Experimental }\end{array}$ & Theoretical \\
\hline 0 & 23 & 2.43 & 2.43 \\
2 & 6.4 & 2.57 & 2.53 \\
4 & 4.8 & 2.65 & 2.62 \\
6 & 4.1 & 2.69 & 2.69 \\
\hline
\end{tabular}

\section{Conclusion}

Nanocrystalline cubic CdS thin films have been successfully deposited by the EICD technique in an aqueous mixture of $\mathrm{CdSO}_{4}, \mathrm{TAA}$ and 2mercaptoethanol (ME) as a surface adsorbent. It is supposed that the growth of each CdS particle was hindered due to the adsorption of ME onto the growing surface of CdS, thus yielding Q-particulate CdS thin films. The size of CdS crystallites could be easily controlled by changing the concentration of the added ME. The deposited Q-particulate films were found to perform as highly active photoelectrodes with increased bandgap energies reasonably expected for their small crystal size.

\section{Acknowledgment}

The present work is partly defrayed by the Grantin-Aid for Scientific Research on Priority-AreaResearch "Electrochemistry of Ordered Interfaces" from the Ministry of Education, Science, Sports and Culture of Japan (09237105). One of the authors (K. Y.) is grateful to Research Fellowship of the Japan Society for the Promotion of Science for Young Scientists.

\section{References}

1) D. Lincot, M. Froment, and H. Cachet, Advances in Electrochemical Science and Engineering (Eds. R. C. 
Alkire and D. M. Kolb), Vol. 6, WILEY-VCH, p. 165 (1999).

2) G. Hodes, Physical Electrochemistry: Principles, Methods, and Applications (Ed. I. Rubinstein), Marcel Dekker Inc., New York, N.Y., p. 515 (1995).

3) K. Yamaguchi, T. Yoshida, T. Sugiura, and H. Minoura, J. Phys. Chem. B, 102, 9677 (1998).

4) J. Rockenberger, L. Troger, A. L. Rogach, M. Tischer, M. Grundmann, A. Eychmuller, and H. Weller, $J$. Chem. Phys., 108, 7807 (1998).

5) Y. Nosaka, J. Phys. Chem., 95, 5054 (1991).

6) H. Yoneyama, Electrochemistry, 67, 324 (1999).

7) R. Vogel, K. Pohl, and H. Weller, Chem. Phys. Lett., 174, 241 (1990).
8) V. Salata, P. J. Dobson, S. Sabesan, P. J. Hull, and J. L. Hutchison, Thin Solid Films, 288, 234 (1996).

9) T. Torimoto, S. Nagakubo, M. Nishizawa, and H. Yoneyama, Langmuir, 14, 7077 (1998).

10) Y. Nosaka, N. Ohta, T. Fukuyama, and N. Fujii, $J$. Colloid Interface Sci., 155, 23 (1993).

11) JCPDS 10-454.

12) JCPDS 6-314.

13) H. F. De Brabander and L. C. Van Poucke, J. Coord. Chem. 3, 301 (1974).

14) G. Hodes, I. D. J. Powell, and L. M. Peter, J. Electrochem. Soc., 139, 3136 (1992).

15) Y.V. Pleskov, Semiconductor Photoelectrochemistry, Consultants Bureau, New York, N.Y., p. 192 (1986). 